\title{
High Emitter Light Duty Vehicle Contributions to On-road Mobile Emissions in 2018 and 2030
}

\author{
Susan Collet ${ }^{1}$, Toru Kidokoro ${ }^{2}$, Yukio Kinugasa ${ }^{2}$, Prakash Karamchandani $^{3}$, Allison DenBleyker ${ }^{3,4}$ \\ ${ }^{1}$ Toyota Motor Engineering and Manufacturing North America, Inc., Ann Arbor, Michigan, USA \\ ${ }^{2}$ Toyota Motor Corporation, Shizuoka, Japan \\ ${ }^{3}$ ENVIRON International Corporation, Novato, California, USA \\ ${ }^{4}$ Now at Eastern Research Group, Inc., Lexington, Massachusetts, USA \\ Correspondence: Susan Collet, Toyota Motor Engineering and Manufacturing North America, Inc., Ann Arbor, \\ Michigan, USA
}

Received: April 28, 2015

doi:10.11114/set.v2i1.838
Accepted: May 12, 2015 Online Published: May 22, 2015

URL: http://dx.doi.org/10.11114/set.v2i1.838

\begin{abstract}
Quantifying the proportion of normal- and high-emitting vehicles and their emissions is vital for creating an air quality improvement strategy for emission reduction policies. This paper includes the California LEV III and United States Environmental Protection Agency Tier 3 vehicle regulations in this projection of high emitter quantification for 2018 and 2030. Results show high emitting vehicles account for up to $6 \%$ of vehicle population and vehicle miles traveled. Yet, they will contribute to over $75 \%$ of exhaust and $66 \%$ of evaporative emissions. As these high emitting vehicles are gradually retired from service and are removed from the roads, the overall effect on air quality from vehicle emissions will be reduced.
\end{abstract}

Keywords: emissions, air quality, regulations, mobile source, emissions reduction

\section{Introduction}

Air quality in the United States (U.S.) has improved since 1980. The U.S. Environmental Protection Agency (EPA) estimates nationwide ambient air pollutant emissions based on actual monitored readings or engineering calculations. Estimates are based on the amounts and types of pollutants emitted by vehicles, factories and other sources. Meanwhile, EPA estimates there are 75 million people which lived in counties nationwide with pollution levels exceeding the primary National Ambient Air Quality Standards (NAAQS) during 2013 (U.S. EPA, 2014a).

Air quality in the U.S. is expected to improve due to EPA's national programs to reduce air emissions. Thus, there are many regulations on-the-way (OTW) and on-the-books (OTB), including regulations on mobile sources, such as the California Low Emission Vehicle third generation (LEV III) and the federal Tier 3 standards. A recent study of Collet et. al (2014a) explored the effects of those regulations by using the U.S. EPA Community Multiscale Air Quality (CMAQ) model to predict maximum daily 8 -hr average ozone concentrations in the western and eastern United States during the years 2018 and 2030 in a month with typical high ozone concentrations, July. The results of their experimentation projected most areas to have decreases in 8-hr ozone concentrations in the year 2030, although there are some areas with increased concentrations. Additionally, there are areas with 8-hr ozone concentrations greater than the current U.S. NAAQS level, which is 75 ppb. These results are consistent with EPA's results (U.S. EPA, 2014b).

A study by the Coordinating Research Council, Inc. (CRC, 2013), simulated light duty gasoline vehicle (LDGV) emissions scenarios with EPA's original light duty vehicle standards. If no controls beyond Tier 0 were implemented through 2022, LDGV emissions would account for $46 \%$ of nitrous oxide $\left(\mathrm{NO}_{\mathrm{x}}\right)$ and $33 \%$ of volatile organic compounds (VOC). However, the additional controls through EPA's second set of light duty vehicle standards, Tier 2, result in LDGV becoming one of the smallest U.S. source sectors for emissions, contributing to $10 \%$ of $\mathrm{NO}_{\mathrm{x}}$ and $8 \%$ of VOC.

California and federal regulations have required the automotive industry to provide consumers with low emission vehicles. Meeting those requirements has required continuous development of emission technologies and necessary improvements to automotive fuels. Explaining advances in vehicle emission control technology aids in understanding why older vehicles have higher emissions than newer vehicles. An article by Ehlmann and Wolff (2005) chronicled the 
most significant improvements applicable to light duty gasoline vehicle emission controls and regulations. The source and chemical composition of automobile emissions were identified as: tailpipe exhaust and emissions contain hydrocarbons ( $\mathrm{HC})$, carbon monoxide (CO) and NOx; and crankcase and evaporative emissions contain $\mathrm{HC}$ only. In the 1960s the positive crankcase ventilation system was implemented as the first control device. In the 1970s the carbon canister, exhaust gas recirculation systems and catalytic converters were implemented. Next, three-way catalytic converters were developed to control $\mathrm{HC}, \mathrm{CO}$ and $\mathrm{NO}_{\mathrm{x}}$ pollutants simultaneously. The three-way catalysis required a high degree of air-fuel ratio control, which created the need for oxygen sensors and replacing carburetors with fuel-injection systems. To ensure acceptable in-use performance, on-board diagnostic (OBD) systems were implemented during the 1980 s and some States also initiated inspection/maintenance (I/M) programs which required owners to have their vehicle's emissions tested and, if the vehicle failed the test, to get it repaired. However, I/M programs have considerable questions about accuracy of the testing and the effectiveness of the repairs. The 1990s introduced requirements to ensure low emissions under the most severe operating conditions.

The tighter tailpipe standards included intermediate mileage (50,000 mile) standards and for the first time, high mileage $(100,000$ mile) standards and OBD II. For these requirements, catalysts were improved to be able to warm-up faster to reduce cold start emissions. Additionally, cleaner low-sulfur gasoline was required to enable advanced technology on new vehicles and provide immediate on-road fleet emission reductions. In the late 1990s, hybrid vehicles were introduced. Some of the advanced technologies used by hybrids include: electric motor drive/assist, regenerative braking and automatic start/shutoff (www.fueleconomy.gov, 2014). In 2013 and 2014, LEV III and Tier 3 standards, respectively, were introduced to reduce emissions to near-zero levels for passenger cars and light-duty trucks and reduce sulfur in gasoline.

The diesel-powered vehicles in the 1970s had a reputation for being high tailpipe emitters. Since then, significant regulations and improvements have been made. Diesel-powered vehicles must now meet the same stringent standards as gasoline vehicles. These standards for $\mathrm{PM}$ and $\mathrm{NO}_{\mathrm{x}}$ in diesel exhaust have helped stimulate major technological advances in diesel engine technology and diesel fuel/lubricant composition, resulting in the emergence of what has been termed New Technology Diesel Exhaust, or NTDE. NTDE is defined as diesel exhaust from post-2006 model year vehicles and older retrofit diesel engines that incorporate a variety of technological advancements, including electronic controls, ultra-low-sulfur diesel fuel, oxidation catalysts, exhaust gas recirculation, wall-flow diesel particulate filters (DPFs), lean $\mathrm{NO}_{\mathrm{x}}$ traps, and selective catalytic reduction (SCR) with urea control (Hesterberg et al., 2011).

The impact of regulations on future mobile source emissions can be predicted using emissions modeling. Therefore, it is important to understand the components of the mobile source model. Mobile sources include all non-stationary sources of air pollution such as cars, trucks, motorcycles, buses, airplanes and locomotives. In general, emissions are calculated as the product of the number of sources population/volume), activity and emission factor (CARB, 2014). The equation is:

$$
\mathrm{E}=\mathrm{Pop} * \mathrm{~A} * \mathrm{EF}
$$

where, $\mathrm{E}=$ pollutant specific emissions [mass emitted per unit time], Pop = population of on-road mobile sources $\mathrm{A}=$ activity (travel data) [e.g. miles traveled per day, or hours operational], $\mathrm{EF}=$ source specific emission factor [mass per unit activity].

Most on-road mobile source inventories for tailpipe and evaporative emissions are estimated by two mathematical modeling tools: the Motor Vehicle Emission Simulator (MOVES) in the U.S. (excluding California) and EMFAC (Emission Factors) model in California. The models contain various modules that account for different portions of the onroad emissions inventory calculation process, specifically population, activity and emission factors, as shown in Figure 1.

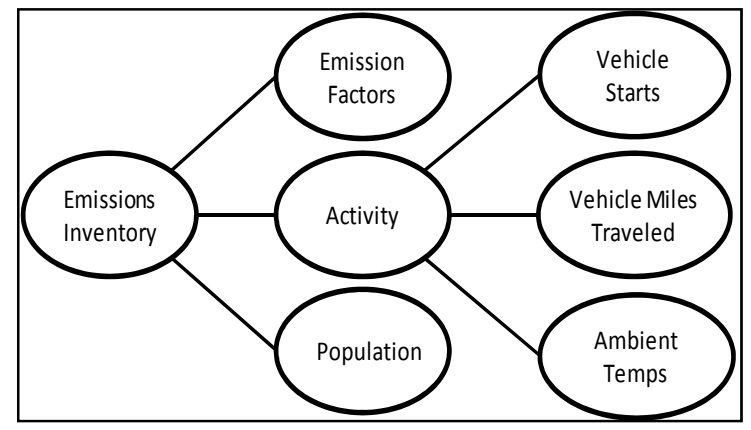

Figure 1. Diagram of the various modules in an emissions model which account for the on-road emission inventory. 
Regarding the population of on-road mobile sources, the models include all fuel type cars, trucks, buses, and motorcycles. In general, population data are obtained from vehicle registration data. These data are compiled and classified according to fuel, class, technology group, age and geographic area. Further calculations require data on population growth rates by calendar year, vehicle class, fuel type and geographic area. These estimates are coupled with activity data and emission factors, as indicated previously, to estimate total emissions. On-road activity refers most commonly to vehicle miles traveled (VMT), speed, and number of trips for each vehicle type and model year. Since motor vehicle emissions are dependent on temperature and humidity profiles, historical meteorological data are utilized. Emission factors used are based on emission tests with dynamometers coupled with certification data to yield base emission rates (BERs) and are adjusted for in-use conditions. There are differences in BERs between EMFAC and MOVES: EMFAC has BERs based on a driving cycle reflecting in-use driving patterns for an average trip and are adjusted by speed correction factors; MOVES has modal emission rates based on speed and vehicle specific power (VSP), which the model uses to calculate a cycle-average emission factor corresponding to the road type and average speed. Emission factors are provided for different temperatures, operating speeds, emission modes, vehicle types, model years, technology types, fuel, and relative humidity. The road type and ramps, fuel formulation, inspection and maintenance programs, and refueling programs are included in the calculation. Evaporative emissions consist of: hot soak loss (HSL) emissions, which are the gasoline vapors generated immediately following shutdown of an engine; diurnal breathing or resting losses (DBL), which are evaporative emissions generated by daily ambient temperature changes while the engine is off; and running losses $(\mathrm{R} / \mathrm{L})$, which are evaporative vapors emitted when the vehicle is in operation (U.S. EPA, 2001). Diesel engines are assumed to have no significant evaporative emissions due to the very low volatility of diesel fuel compared to gasoline (U.S. EPA, 2004). Both EMFAC and MOVES account for particulate matter (PM) associated with tire and brake wear. Therefore, all in-use aspects of on-road vehicle emissions are accounted for in the modeling.

On-road vehicle emissions are estimated by State and local air quality and transportation agencies for a variety of different regulatory purposes. Inventories are required as the basis for showing further progress, attainment demonstration, and maintenance in their State Implementation Plans (SIPs). On-road emissions are calculated as part of the regional conformity analysis for transportation plan and transportation improvement program (TIP) conformity determinations, and the regional emissions analysis associated with projects in isolated rural areas.

Consequently, it is important to know if a small fraction of motor vehicles on the roadway emits a disproportionate fraction of pollutant emissions, especially since it is possible for the difference in emissions between normal- and high-emitting vehicles to differ by one or more orders of magnitude (Wolf et al., 1998). Quantifying the proportion of normal- and high-emitting vehicles is vital for creating a strategy for air quality improvement via improved emission reduction policies that target subsets of the vehicle fleet. Research literature provides wide ranges of estimated contributions from these high emitters, but the general conclusion is that a small fraction of the fleet is responsible for a significant fraction of fleet emissions. The objective of this study was to determine, with the promulgation of California Air Resources Board's LEV III and U.S. EPA's Tier 3, the projected percentage of high emitters and their contribution to emissions of pollutants affecting air quality.

\section{Methodology}

This study investigated the impact of high-emitter vehicles on the on-road emissions inventory in 2018 and 2030. For this effort, a literature search was performed to compile emission rates by age (by vehicle, model and year) for normal-emitters, high-emitters, and repaired high-emitters, as well as fractions of vehicle population by model year considered to be high-emitter and repaired high-emitter (U.S. EPA, 1999; SEMCOG, 2008; Brooks, 1995; Hawkins, 2013). The scope of this effort was defined to include exhaust and evaporative $\mathrm{HC}, \mathrm{NO}_{\mathrm{x}}$ and $\mathrm{PM}$. Tier 3 vehicles were projected to have the same trends as found in the literature for Tier 1 and Tier 2 vehicles. The vehicle types in the analysis were limited to the light duty vehicle categories as follows:

1. LDGV (light duty gasoline vehicles; passenger cars);

2. LDGT1 (light duty gasoline truck classes 1 and 2);

3. LDGT2 (light duty gasoline truck classes 3 and 4);

4. LDDV (light duty diesel vehicles);

5. LDDT (light duty diesel truck classes 1-4).

Heavy duty diesel and gasoline vehicles (HDDV and HDGV) were not included in the high emitter analysis.

It was estimated, for 2018 and 2030 calendar year, new vehicles emit within normal levels until they are one year old at which time the percent of high emitters in the fleet is relatively low ( 0.5 or $0.6 \%$ of the age group population). The percent of high emitters then increases with vehicle age, accumulating linearly with age until 20 -years old. Figure 2 
illustrates an example of gasoline passenger car (LDGV) populations by emitter category in the year 2018. From left to right, vehicle ages 0 (new) to 30 years old are shown with the percent of each age group's population by emitter category on the primary y-axis (left side). Figure 2 also shows the 2018 calendar year relative VMT by age on the secondary y-axis (right side). It illustrates that most of the vehicle activity is from younger vehicles and younger vehicles tend to emit normally.

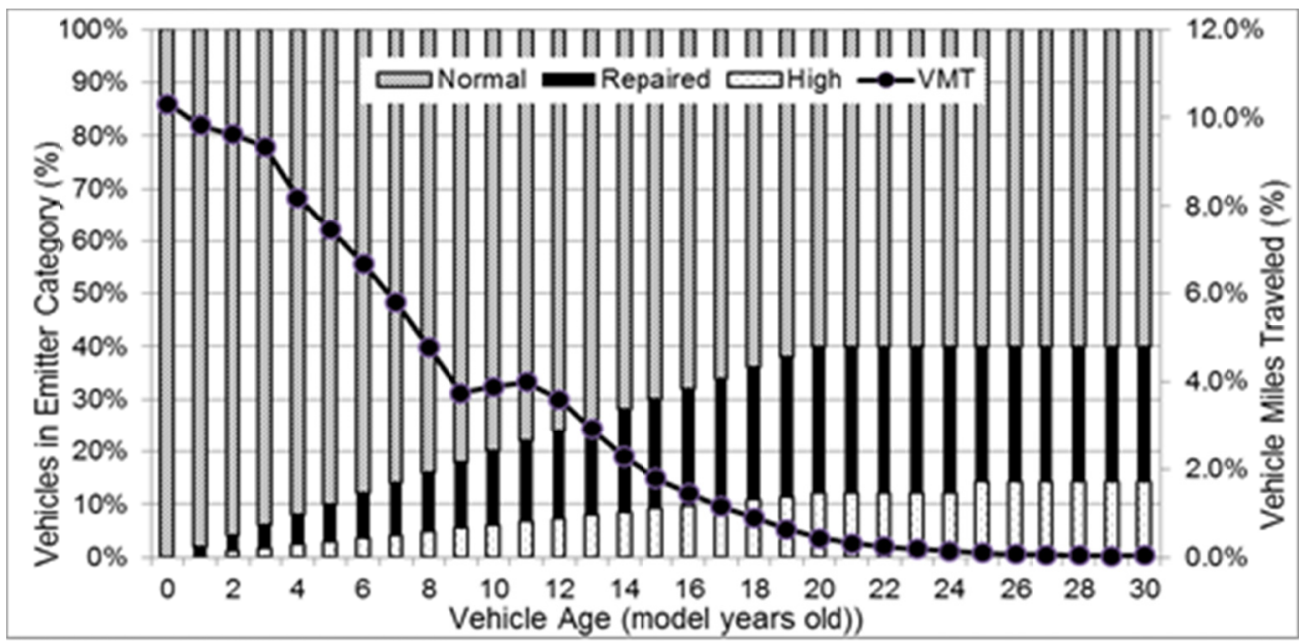

Figure 2. Percent of LDGVs by age in each emitter category, superimposed with 2018 percentage of vehicle miles travel by age. Vehicle age zero is model year 2018 and vehicle age 30 is model year 1988.

In addition to the fleet population and VMT activity fractions, estimates of the emission rates for high-emitters, repaired high-emitters and normal-emitters by vehicle age were compiled. Figure 3 shows an example of the $\mathrm{NO}_{\mathrm{x}}$ emission rates by age from LDGVs in calendar year 2018. The high-emitters were defined as 2 grams per mile $(\mathrm{g} / \mathrm{mi}) \mathrm{NO}_{\mathrm{x}}$ on the Federal Test Procedure (FTP). Normal-emitter and repaired-emitter emission rates are similar with respect to vehicle age.

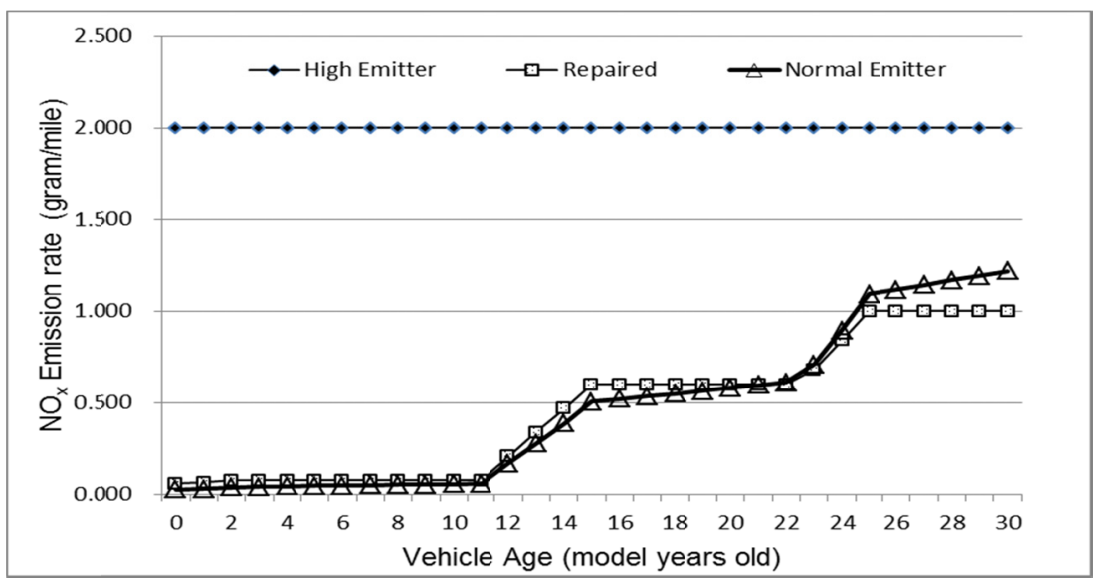

Figure 3. $\mathrm{LDGV} \mathrm{NO}_{\mathrm{x}}$ emission rates by vehicle age for each emitter category in calendar year 2018. Vehicle age zero is model year 2018 and vehicle age 30 is model year 1988.

Next, emission rates were multiplied by the activity, i.e. with the population or VMT, for each emitter category to estimate the emissions from each emitter group. The activity was projected from the MOVES (version: MOVES2010a) model (EPA, 2010). The future year projections generated by the model were based on changes expected due to implementation of regulations as well as growth projections and were the same as those explained in Collet et al. (2014b). In a final processing step, the emissions were summed for each emitter category over all vehicle ages.

\section{Results}

California has different vehicle emission requirements than other areas of the U.S. Subsequently, the portion of emissions attributed to high-emitters is different between California and the rest of the U.S. So, the high emitter analysis was conducted separately for California and other U.S. areas. The results from the high emitter calculations for federal LDGV standards are shown in Figure 4, while all the vehicle results for federal and California standards are shown in Tables 1 and 2, respectively. Only the high-emitter emission percentages are shown; the remaining normal-emitter and 
repaired vehicle emissions are together considered normal-emitters for purposes of splitting the on-road emission inventory, because the repaired vehicles have emission rates similar to normal-emitters after repair, as shown in Figure 5. The results show the high emitter population is 5 to $6 \%$, and accounts for 3 to $5 \%$ of VMT. This is the case in 2018 and 2030, in California and the rest of the U.S. Depending on the vehicle type, the contributions of high emitters in California in 2018 range from: 51 to 66\% for exhaust HC emissions; 48 to 66\% for PM emissions; 40 to $52 \%$ for NOx emissions; and 58 to $61 \%$ for evaporative HC emissions. In the rest of the U.S., the high-emitter contributions in 2018 are somewhat different and range from: 38 to $46 \%$ for exhaust $\mathrm{HC}$ emissions; 37 to $46 \%$ for PM emissions; 25 to $46 \%$ for NOx emissions; $42 \%$ to $43 \%$ for evaporative $\mathrm{HC}$ emissions from running losses; and 67 to $74 \%$ for evaporative $\mathrm{HC}$ emissions from hot soak and diurnal losses.

The relative high-emitter contributions in 2030 are projected to be higher than those in 2018 in both California and the rest of the U.S., even though the relative high-emitter populations and activities in the two future years are similar. This is due to new vehicle emissions in 2030 will be lower than those in 2018 because of the phase-in for Tier 3 and LEV III regulations, thus increasing the relative contributions of high-emitters. In 2030, the contributions of high emitters in California range from: 79 to $83 \%$ for both exhaust $\mathrm{HC}$ emissions and PM emissions, 73 to $77 \%$ for NOx emissions, and 65 to $68 \%$ for evaporative $\mathrm{HC}$ emissions. In the rest of the U.S., high emitter contributions range from: 67 to $75 \%$ for exhaust $\mathrm{HC}$ emissions and PM emissions, 62 to $76 \%$ for NOx emissions, 45 to $50 \%$ for evaporative $\mathrm{HC}$ emissions from running losses, and 78 to $84 \%$ for evaporative $\mathrm{HC}$ emissions from hot soak and diurnal losses. The PM and HC exhaust percentages are similar because high emitter emission rates for both pollutants were the same multiple of the normal emitter rates by model year.

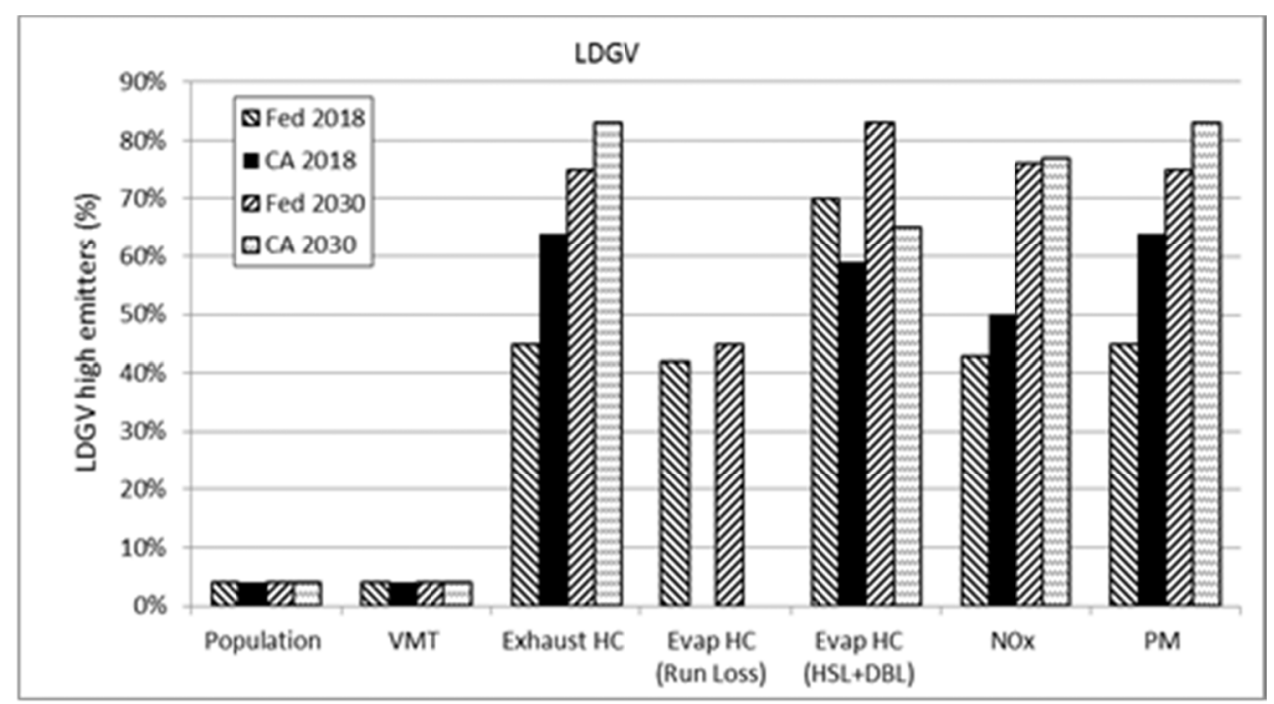

Figure 4. Percent of high emitters in the LDGV contribution by population, VMT, and for $\mathrm{HC}, \mathrm{NO}_{\mathrm{x}}$ and PM. Table 1. Results of Light Duty Vehicle High Emitter Analysis for HC, NOx, and PM: Federal outside California.

\begin{tabular}{|c|c|c|c|c|c|c|c|}
\hline Vehicle & Population & VMT & Exhaust HC & $\begin{array}{l}\text { Evaporative HC } \\
(\mathrm{R} / \mathrm{L})\end{array}$ & $\begin{array}{l}\text { Evaporative HC } \\
\text { (HSL+DBL) }\end{array}$ & $\mathrm{NO}_{\mathrm{x}}$ & PM \\
\hline \multicolumn{8}{|l|}{2018} \\
\hline LDGV & $4 \%$ & $4 \%$ & $45 \%$ & $42 \%$ & $70 \%$ & $43 \%$ & $45 \%$ \\
\hline LDGT1 & $6 \%$ & $3 \%$ & $39 \%$ & $43 \%$ & $74 \%$ & $32 \%$ & $39 \%$ \\
\hline LDGT2 & $6 \%$ & $5 \%$ & $39 \%$ & $43 \%$ & $67 \%$ & $25 \%$ & $37 \%$ \\
\hline LDDV & $4 \%$ & $3 \%$ & $46 \%$ & & & $46 \%$ & $46 \%$ \\
\hline LDDT & $6 \%$ & $5 \%$ & $38 \%$ & NA & & $28 \%$ & $38 \%$ \\
\hline \multicolumn{8}{|l|}{2030} \\
\hline LDGV & $4 \%$ & $4 \%$ & $75 \%$ & $45 \%$ & $83 \%$ & $76 \%$ & $75 \%$ \\
\hline LDGT1 & $6 \%$ & $3 \%$ & $68 \%$ & $50 \%$ & $84 \%$ & $66 \%$ & $68 \%$ \\
\hline LDGT2 & $6 \%$ & $5 \%$ & $69 \%$ & $50 \%$ & $78 \%$ & $61 \%$ & $69 \%$ \\
\hline LDDV & $4 \%$ & $4 \%$ & $75 \%$ & NA & & $76 \%$ & $75 \%$ \\
\hline LDDT & $6 \%$ & $5 \%$ & $67 \%$ & NA & & $62 \%$ & $67 \%$ \\
\hline
\end{tabular}


Table 2. Results of Light Duty Vehicle High Emitter Analysis for $\mathrm{HC}, \mathrm{NO}_{\mathrm{x}}$, and PM: California.

\begin{tabular}{|c|c|c|c|c|c|c|}
\hline Vehicle & Population & VMT & Exhaust HC & Evaporative $\mathrm{HC}$ & $\mathrm{NO}_{\mathrm{x}}$ & PM \\
\hline \multicolumn{7}{|l|}{2018} \\
\hline LDGV & $4 \%$ & $4 \%$ & $64 \%$ & $59 \%$ & $50 \%$ & $64 \%$ \\
\hline LDGT1 & $6 \%$ & $3 \%$ & $57 \%$ & $61 \%$ & $43 \%$ & $57 \%$ \\
\hline LDGT2 & $6 \%$ & $5 \%$ & $51 \%$ & $58 \%$ & $40 \%$ & $48 \%$ \\
\hline LDDV & $4 \%$ & $3 \%$ & $66 \%$ & \multirow{3}{*}{ NA } & $52 \%$ & $66 \%$ \\
\hline LDDT & $6 \%$ & $5 \%$ & $54 \%$ & & $44 \%$ & $54 \%$ \\
\hline \multicolumn{6}{|l|}{2030} & \\
\hline LDGV & $4 \%$ & $4 \%$ & $83 \%$ & $65 \%$ & $77 \%$ & $83 \%$ \\
\hline LDGT1 & $6 \%$ & $3 \%$ & $81 \%$ & $68 \%$ & $73 \%$ & $81 \%$ \\
\hline LDGT2 & $6 \%$ & $5 \%$ & $80 \%$ & $66 \%$ & $73 \%$ & $80 \%$ \\
\hline LDDV & $4 \%$ & $4 \%$ & $83 \%$ & \multirow{2}{*}{ NA } & $77 \%$ & $83 \%$ \\
\hline LDDT & $6 \%$ & $5 \%$ & $79 \%$ & & $73 \%$ & $79 \%$ \\
\hline
\end{tabular}

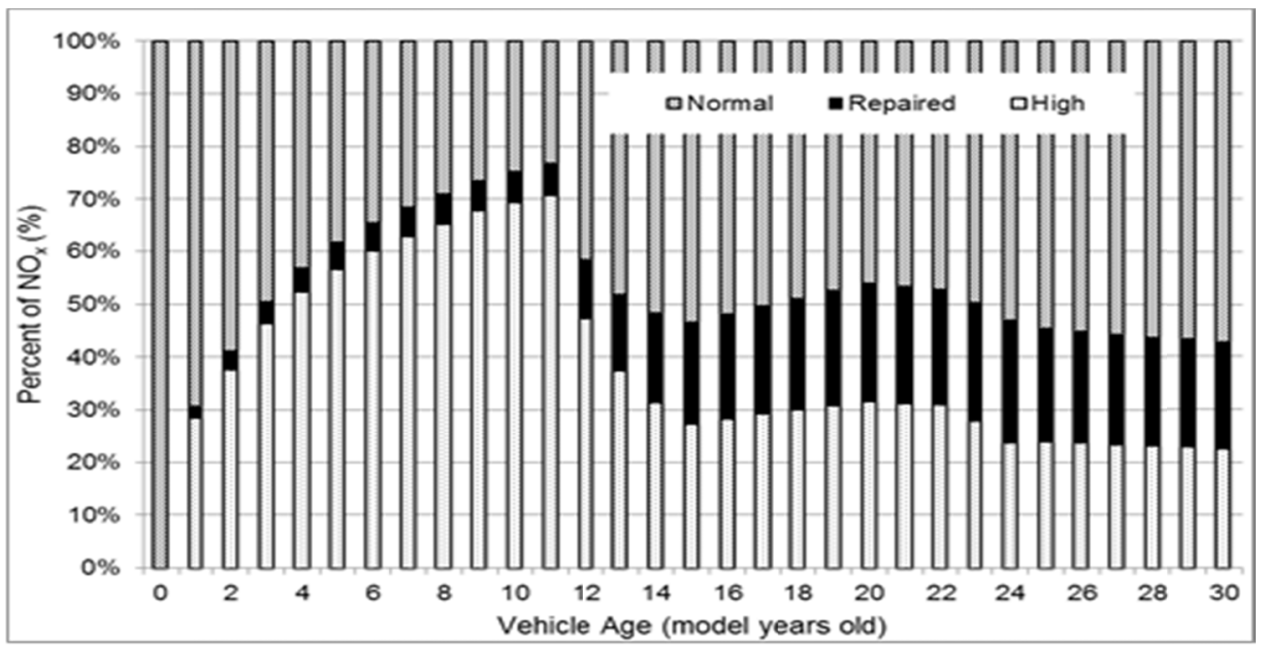

Figure 5. Percent of LDGV NO ${ }_{x}$ emissions in each emitter category by vehicle age, for calendar year 2018. Vehicle age zero is model year 2018 and vehicle age 30 is model year 1988.

\section{Discussion}

Quantifying the proportion of normal- and high-emitting vehicles is vital for creating a strategy for air quality improvement via policies that target subsets of the vehicle fleet. In 2018 and 2030, a very small percentage of vehicles for both population and VMT - are high emitting vehicles. However, these vehicles contribute a disproportionate amount (up to $83 \%$ ) of the on-road vehicle emissions. As these high emitting vehicles are gradually retired and are removed from the roads, the overall effect on air quality from vehicle emissions will be reduced.

\section{References}

Brooks, D., Baldus, S., Bandy, W., Peltier, R., Reuter, R. M., \& Sprik, T. L. (1995). Real World Hot Soak Evaporative Emissions - A Pilot Study. SAE Technical Paper 951007. http://dx.doi.org/10.4271/951007

\section{CARB (California Air Resources Board). Emission Inventory Description,} http://www.arb.ca.gov/planning/sip/2007sip/apr07draft/revdrftappf.pdf, (accessed 8 Aug 2014).

Collet, S., Minoura, H., Kidokoro, T., Sonada, Y., Kinugasa, Y., Karamchandani, P., Johnson, J., Shah, T., Jung, J., \& DenBleyker, A. (2014b). Future Year Ozone Source Attribution Modeling Studies for the Eastern and Western United States, Journal of the Air \& Waste Management Association, 64(10), 1174-1185, http://dx.doi.org/10.1080/10962247.2014.936629

Collet, S., Minoura, H., Kidokoro, T., Sonoda, Y., Kinugasa, Y., \& Karamchandani, P. (2014a). Evaluation of light-duty vehicle mobile source regulations on ozone concentration trends in 2018 and 2030 in the western and eastern United States. Journal of the Air \& Waste Management Association 64(2), 175-183, http://dx.doi.org/10.1080/10962247.2013.845621

CRC, Inc. (2013). Effects of Light-Duty Vehicle Emissions on Ozone and PM with Past, Present, and Future Controls:
Tier
$0 \quad$ versus
Other
Scenarios,
27-44.

http:/www.crcao.com/reports/recentstudies2013/A-76-2/CRC\%20Project\%20A76-2\%20Final\%20Report.pdf 
Ehlmann, J., \& Wolff, G. (2005). Automobile Emissions, The Road Toward Zero, “em”, Air and Waste Management, 33- 35 .

Hawkins, D. (2013). Modeling Vapor Emissions during Hot Soak Operation from Leaking Vehicles. FACA MOVES Review Workgroup, $\quad$ U.S. EPA. http://www.epa.gov/oms/models/moves/documents/faca-meeting-jan2013/06-hot-soak-with-leaks-notes.pdf (accessed 12 Sept 2014)

Hesterberg, T. W., Long, C. M., Sax, S. N., Lapin, C. A., McClellan, R. O., Bunn, W. B., \& Valberg, P. A. (2011). Particulate Matter in New Technology Diesel Exhaust (NTDE) is Quantitatively and Qualitatively Very Different from that Found in Traditional Diesel Exhaust (TDE), Journal of the Air \& Waste Management Association, 61(9), 894-913, http://dx.doi.org/10.1080/10473289.2011.599277

SEMCOG, the Southeast Michigan Council of Governments. (2008). Passenger Vehicles and Air Pollution; A profile of Southeast Michigan's Fleet, 2-3

U. S. EPA. (1999). Development of Light-Duty Emission Inventory Estimates in the Notice of Proposed Rulemaking for Tier 2 and Sulfur Standards, EPA420-R-99-005, 5-8.

U.S. EPA (2001). Estimating Running Loss Evaporative Emissions in MOBILE6. http://www.epa.gov/otaq/models/mobile6/r01023.pdf, (accessed 8 Aug 2014).

U.S. EPA (2004). Basic Evaporative and Crankcase Emission Rates for Nonroad Engine Modeling. http://www.epa.gov/otaq/models/nonrdmdl/nonrdmdl2004/420p04012.pdf, (accessed 8 Aug 2014)

U.S. EPA (2010). User Guide for MOVES2010a. EPA-420-B-10-036. 2010. Research Triangle Park, NC: Office of Transportation and Air Quality, U.S. Environmental Protection Agency.

U.S. EPA (2014a). Air Quality Trends, http://www.epa.gov/air/airtrends/aqtrends.html\#comparison (accessed 11 Nov 2014).

U.S. EPA. (2014b). Air Quality Modeling Technical Support Document: Tier 3 Motor Vehicle Emission and Standards, http://www.epa.gov/otaq/documents/tier3/454r14002.pdf, (accessed 8 Aug 2014).

Wolf, J., Guensler, R., Washington, S., \& Bachman, W. (1998). High-emitting vehicle characterization using regression tree analysis, Transportation Research Record, 1641, 98-1213.

\section{(cc) $\overline{E Y}$}

This work is licensed under a Creative Commons Attribution 3.0 License. 